\title{
Quebra de dormência de sementes da videira cv. niágara rosada sem estratificação
}

\author{
Aurinete Daienn Borges do Val $^{1}$ Sérgio Yoshimitsu Motoike ${ }^{2}$ Eveline Mantovani Alvarenga ${ }^{3}$, \\ Paulo Roberto Cecon ${ }^{4}$
}

\begin{abstract}
RESUMO
O objetivo deste trabalho foi verificar o efeito de três fatores na germinação de sementes de uva cv. niágara rosada: tratamentos físicos, tratamentos químicos e ambientes de germinação. Os tratamentos físicos consistiram de sementes com corte transversal na região mediana e de sementes com corte na micrópila. Os tratamentos químicos foram aplicados mediante imersão das sementes inteiras em solução aquosa de ácido giberélico $\left(\mathrm{GA}_{3}\right)$ nas concentrações de 0 e $4000 \mathrm{mg} \mathrm{L}^{-1}$. Os ambientes avaliados foram in vitro e ex vitro. O experimento foi um fatorial do tipo $2 \times 2 \times 2$ no delineamento em blocos ao acaso, com quatro repetições, sendo a parcela experimental constituída de um Gerbox ${ }^{\circledR}$, contendo 25 sementes ou uma grade com 25 tubos de ensaio. Os parâmetros avaliados foram porcentagem e velocidade de germinação das sementes. Os resultados indicaram que o corte das sementes é imprescindível à germinação de sementes não estratificadas. A combinação entre cortes na micrópila, $4000 \mathrm{mg} \mathrm{L}^{-1}$ de $\mathrm{GA}_{3}$ e ambiente in vitro, proporcionou a germinação de $77 \%$ das sementes, sendo o ambiente in vitro significativamente superior ao ex vitro.
\end{abstract}

Palavras-chave: Vitis labruscana L.H. Bailey, uvas, germinação, in vitro, giberelinas

\section{ABSTRACT}

\section{Breaking the dormancy of niagara rosada seeds without stratification}

The objective of this study was to asses the effect of three factors on the germination of grape seeds, cv. Niagara Rosada. The three studied factors were: physical treatments, chemical treatments and germination environment. The physical treatments consisted of whole seeds, seeds with a cross cut in the median region and seeds with a cut in the micropyle. The chemical treatments were applied by immersing whole seeds in aqueous solution of gibberellic acid $\left(\mathrm{GA}_{3}\right)$ with concentrations of 0 and $4000 \mathrm{mg} \mathrm{L}^{-1}$. The environments evaluated were in vitro and ex vitro. The experiment was arranged in a factorial $3 \times 2 \times 2$, randomized blocks design, with 4 repetitions, each one consisting of a Gerbox ${ }^{\circledR}$ containing 25 seeds or a rack with 25 test tubes. The parameters evaluated were the percentage and speed of seed germination. The results showed that cutting is essential to the germination of non-stratified seeds. The combination micropyle cut, $4000 \mathrm{mg} \mathrm{L}^{-1}$ of $\mathrm{GA}_{3}$ and in vitro environment resulted in $77 \%$ of seed germination. The in vitro environment was significantly superior to the ex vitro environment.

Key words: Vitis labruscana L.H. Bailey, germination, in vitro, gibberellins

\footnotetext{
Recebido para publicação em dezembro de 2006 e aprovado em novembro de 2009

${ }^{1}$ Engenheira-Agrônoma, Mestranda. Departamento de Fitotecnia, Universidade Federal de Viçosa, Av. P. H. Rolfs s/ nº, 36570-000, Viçosa, Minas Gerais, Brasil. aurineteval@yahoo.com.br

${ }^{2}$ Engenheiro-Agrônomo, Ph.D. Departamento de Fitotecnia, Universidade Federal de Viçosa, Av. P. H. Rolfs s/nº, 36570-000, Viçosa, MG, Brasil. motoike@ufv.br

${ }^{3}$ Engenheira-Agrônoma, Mestre. Departamento de Fitotecnia. Universidade Federal de Viçosa, Av. P.H.Rolfs s/ no , 36570-000, Viçosa, MG, Brasil. eveline@ufv.br

${ }^{4}$ Engenheiro-Agrônomo, Doutor. Departamento de Informática, Universidade Federal de Viçosa, Av. P.H. Rolfs s/nº, 36570-000, Viçosa, MG, Brasil. cecon@dpi.ufv.br
} 


\section{INTRODUÇÃO}

O melhoramento genético da videira, como de outras espécies vegetais, tem em sua essência a realização de hibridações controladas para gerar a necessária variabilidade. Devido às características morfoanatômicas de sua flor, esse procedimento é árduo e meticuloso.

Para a realização de hibridações controladas na cultura da videira, é necessária a emasculação (eliminação do androceu) nos genitores femininos, uma vez que nos cultivares comerciais as flores são hermafroditas. Devido à inflorescência da videira ser do tipo cacho com botões florais minúsculos e em grande número, o rendimento operacional da emasculação é muito baixo, além de exigir pessoal especializado para o trabalho. Em média, são realizados em torno de 10 cachos em um dia de trabalho. Além disso, o período em que os estigmas estão receptivos, que é em torno de três dias, obriga que as operações de cruzamentos sejam realizadas nesse curto espaço de tempo. Outro aspecto é o baixo número de sementes produzidas pela baga da uva, que é de no máximo quatro, o que leva a necessidade de se realizar grandes números de cruzamentos.

Se não bastasse essa problemática, as sementes de videira apresentam baixos índices de germinação. Ergenoglu et al. (1997), estudando a germinação de sementes de Vitis vinifera cvs. cardinal, tarsus bevari e itália durante dois anos, obtiveram no tratamento controle a percentagem de germinação média de 5,9, 2,0 e 4,4, respectivamente. Pommer et al. (1988), estudando o efeito da estratificação na germinação de sementes de Vitis labruscana cv. niagara rosada, observaram que as sementes do tratamento testemunha não germinaram.

A baixa germinação da semente de uva tem sido atribuída pela maior parte dos autores, incluindo Ellis et al. (1983), Gray \& Meredith (1992) e Reisch \& Pratt (1996), à dormência da semente. Segundo esses autores, a estratificação ( 3 a $5{ }^{\circ} \mathrm{C}$ ) por intervalos de 60 a 90 dias é o método mais utilizado para a quebra de dormência da semente da uva. Porém, esse tratamento raramente promove a germinação de todas as sementes, ficando a média em torno de 50\% (Ellis et al., 1983).

Portanto, o baixo índice de germinação da semente de uva constitui-se, atualmente, em um gargalo do processo de melhoramento genético da videira, o qual tem de ser compensado pela realização de cruzamentos em maior número de inflorescências para a obtenção de progênies com um número mínimo de indivíduos para posterior seleção.

Sendo assim, o objetivo deste trabalho foi estudar métodos alternativos de germinação de sementes de videira, visando aumentar a eficiência do processo. Desta forma, avaliaram-se o ambiente (in vitro e ex vitro), os tratamentos químicos e físicos na velocidade e a porcentagem de germinação de sementes de videira, cv. niagara rosada.

\section{MATERIAL E MÉTODOS}

O presente trabalho foi realizado no Laboratório de Cultura de Células e Tecidos Vegetais do Departamento de Fitotecnia da Universidade Federal de Viçosa e constituiu no estudo de três fatores para aumentar a germinação de sementes de videira cv. niágara rosada. Estes fatores foram: ambiente de germinação (ex vitro e in vitro), tratamentos físicos (sementes cortadas no meio e cortadas na região da micrópila) e químicos (0 e $4000 \mathrm{mg} \mathrm{L}^{-1} \mathrm{de}_{\mathrm{GA}_{3}}$ ).

As sementes utilizadas neste experimento foram extraídas e selecionadas a partir de frutos maduros adquiridos no comércio local. Elas foram removidas manualmente das bagas, lavadas em água corrente e postas para secar sobre papel toalha, em condição ambiente, onde permaneceram por uma noite. Passado esse tempo, as sementes inteiras foram desinfetadas e, posteriormente, submetidas aos tratamentos com ácido giberélico. O protocolo de desinfestação consistiu na imersão delas em uma solução de fungicida Captan 500 PM mais água, na proporção de 2,5\% (p/v), por um período de 15 minutos, e de álcool etílico hidratado $92,8^{\circ}$, por um minuto, seguidas de hipoclorito de sódio a $5 \%$ por 40 minutos. As imersões em cada uma das soluções eram seguidas de três enxaguaduras com água desionizada estéril.

Os tratamentos químicos foram aplicados mediante imersão das sementes inteiras de em solução aquosa de ácido giberélico $\left(\mathrm{GA}_{3}\right)$ nas concentrações descritas e deixadas em repouso por 24 horas em ambiente sem luz, antes do tratamento físico. Após o período de embebição nas soluções de $\mathrm{GA}_{3}$, as sementes inteiras foram retiradas das soluções, seccionadas e inoculadas nos respectivos substratos. Toda essa operação foi realizada no interior de câmara de luxo laminar.

$\mathrm{O}$ ambiente in vitro caracterizava-se pela temperatura e pelo fotoperíodo da sala de cultivo controlados em 27 ${ }^{\circ} \mathrm{C}$ e 16/8 h de luz/escuro, respectivamente. A irradiância, fornecida por tubos fluorescentes de $40 \mathrm{~W}$ de potência, estava em torno de $\pm 52 \mu \mathrm{Mol} \mathrm{m}^{-2} \mathrm{~s}^{-1}$. O substrato utilizado foi o meio contendo os sais minerais de MS (Murashige \& Skoog, 1962), vitaminas de White (1951), 2,5 $\mathrm{g} \mathrm{L}^{-1} \mathrm{de}$ carvão ativado, $30 \mathrm{~g} \mathrm{~L}^{-1}$ de sacarose, $100 \mathrm{mg} \mathrm{L}^{-1}$ de mioinositol e ágar Isofar $8 \mathrm{~g} \mathrm{~L}^{-1}$. O pH do meio utilizado foi ajustado para 5,7 $\pm 0,1$ antes da distribuição nos tubos de ensaio (24,5 x $150 \mathrm{~mm}$ ) e então autoclavado durante 20 minutos à temperatura de $121^{\circ} \mathrm{C}$. Foram utilizados $10 \mathrm{~mL}$ de meio por tubo e uma semente/tubo.

$\mathrm{O}$ ambiente ex vitro consistiu em um aparelho BOD. O substrato utilizado foi o Plantmax ${ }^{\circledR}$, distribuído em caixas de Gerbox ${ }^{\circledR}$ de dimensões 63 x $98 \mathrm{~mm}$. Foram usados $50 \mathrm{~g}$ do substrato/recipiente. Após a distribuição do substrato, esse foi autoclavado durante 30 minutos à temperatura de 
$121{ }^{\circ} \mathrm{C}$. As condições de temperatura, fotoperíodo e irradiância do BOD foram semelhantes às encontradas na sala de cultivo in vitro.

O delineamento experimental foi em blocos ao acaso em esquema fatorial $2 \times 2 \times 2$, com quatro repetições, e parcela experimental constituída de um Gerbox ${ }^{\circledR}$ contendo 25 sementes ou uma grade com 25 tubos de ensaio cada.

O período de avaliação do experimento foi de 28 dias, durante o qual foram realizadas quatro contagens do número de sementes germinadas. A primeira ocorreu aos sete dias após a inoculação, e as demais aos 14 , 21 e 28 dias.

Foram realizadas as seguintes avaliações: porcentagens de germinação e velocidade de germinação (VG), em dias. A velocidade de germinação foi calculada pela fórmula apresentada por Vieira \& Carvalho (1994):

$\mathrm{VG}=(\mathrm{N} 1 . \mathrm{G} 1)+(\mathrm{N} 2 . \mathrm{G} 2)+\ldots+(\mathrm{Nn} \cdot \mathrm{Gn})$,

em que:

$\mathrm{G} 1+\mathrm{G} 2+\ldots+\mathrm{Gn}$

G1, G2, ..., Gn = número de plântulas normais computadas na primeira, segunda e última contagens e;

$\mathrm{N} 1, \mathrm{~N} 2, \ldots, \mathrm{Nn}=$ número de dias de semeadura à primeira, segunda e última contagens

Apenas as sementes que originaram plântulas normais foram consideradas na avaliação.

Os dados foram submetidos aos testes de Liliefors e de Cochran para verificação da normalidade e homogeneidade da variância. Atendidas essas exigências, os dados foram submetidos à análise de variância, utilizando-se o teste $\mathrm{F}$ a $5 \%$ de probabilidade. As médias foram comparadas utilizando o teste de Tukey a 5\% de probabilidade.

\section{RESULTADOS E DISCUSSÃO}

Foi observado que, em geral, a germinação das sementes cortadas ao meio caracterizou-se pela emissão do caulículo, seguida pela protrusão da radícula, enquanto as sementes submetidas ao corte na micrópila apresentaram comportamento contrário, com a protrusão radicular antecedendo à caulicular. Nesse caso, a emissão da radícula iniciou-se após 24 horas de instalação do experimento.

Também foi possível observar que em ambiente ex vitro as sementes iniciaram a germinação da mesma forma que nas condições in vitro, porém em algumas sementes o processo foi paralisado logo no início, não havendo a total emissão da radícula ou do caulículo.

Segundo Terra et al. (1993) e Reisch \& Pratt (1996), o tegumento de sementes de videira é duro, de espessura variável e rico em tanino, substância que, de acordo com Carvalho \& Nakagawa (2000), juntamente com a suberina, lignina, cutina, pectina e outros derivados da quinona, são exemplos de compostos presentes no tegumento das sementes que conferem impermeabilidade à água.

O corte das sementes da videira, seja no meio ou na região da micrópila, rompeu esse tegumento e, provavelmente, permitiu que inibidores fossem lixiviados das sementes e que a água, o oxigênio e os demais nutrientes alcançassem o embrião, desencadeando o processo da germinação. Pode-se verificar também que o corte pode substituir com vantagem a estratificação das sementes, já que elas germinaram sem esse tratamento.

Dentre as vantagens da aplicação do tratamento de corte das sementes, é evidente o ganho no tempo e na uniformidade da germinação, que é parâmetro desejável em um programa de melhoramento genético. Em métodos convencionais utilizados atualmente, gastam-se de 60 a 90 dias para a estratificação das sementes, e a germinação pós-estratificação ocorre de forma desuniforme, podendo, o processo, como um todo, ultrapassar 120 dias (Ellis et al., 1983; Gray \& Meredith, 1992; Reisch \& Pratt, 1996).

Neste trabalho, as sementes submetidas aos cortes completaram a germinação dentro do período de quatro semanas, sendo a menor velocidade de germinação observada de 16,5 dias e a maior de 8 dias (Figura 2). Entretanto, não houve diferença significativa na velocidade de germinação em função das diferentes modalidades de cortes ou de tratamentos químicos aplicados às sementes (Figuras 1 e 2). Contudo, em ambiente in vitro a velocidade de germinação de sementes cortadas na região da micrópila, embebidas ou não com $\mathrm{GA}_{3}$, foi, em media, 8,30 e 6,50 dias, respectivamente, superior em relação ao ambiente ex vitro (Figura 3).

A porcentagem de germinação de sementes de uva submetidas aos cortes variou, em função dos tratamentos aplicados, entre 19,5 e 77\% (Figura 4). O efeito do

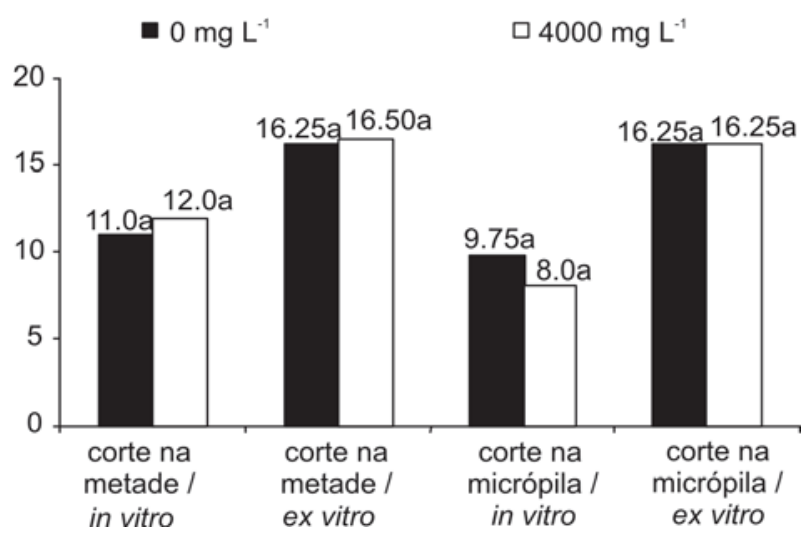

Figura 1. Efeito das concentrações de ácido giberélico na velocidade de germinação (em dias) de sementes de videira cv. niágara rosada. As médias seguidas da mesma letra e que correspondem à mesma combinação dos tratamentos não diferem entre si, pelo teste de Tukey, a 5\% de probabilidade 


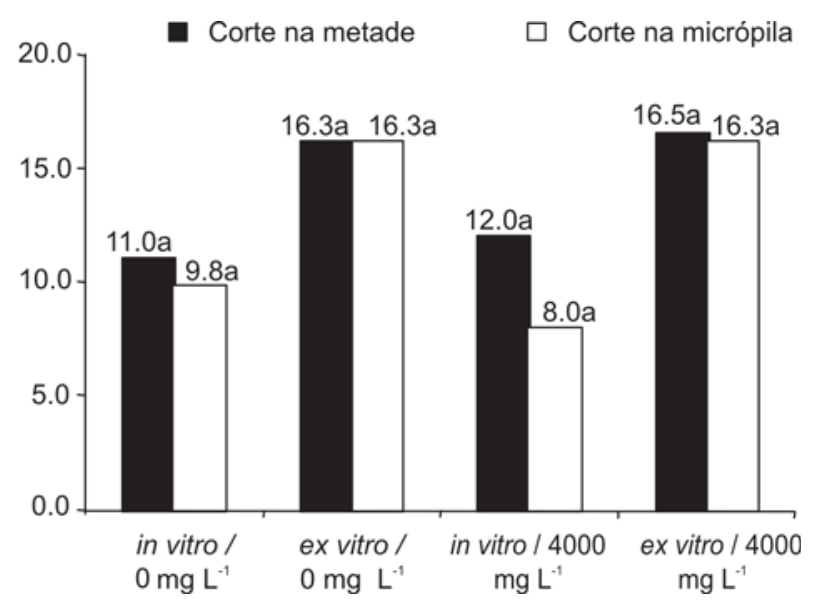

Figura 2. Efeito dos tratamentos físicos na velocidade de germinação (em dias) de sementes de videira cv. niágara rosada. As médias seguidas da mesma letra e que correspondem à mesma combinação dos tratamentos não diferem entre si, pelo teste de Tukey, a 5\% de probabilidade

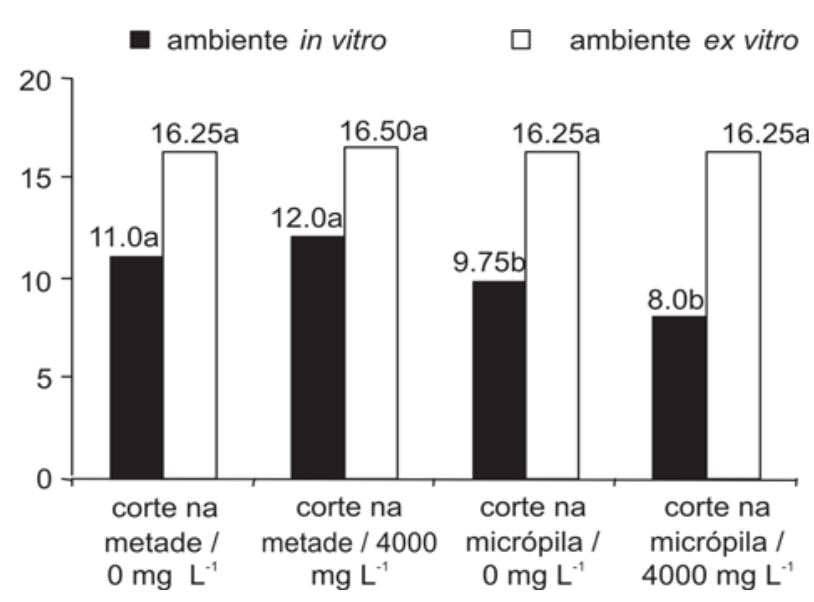

Figura 3. Efeito dos ambientes na velocidade de germinação (em dias) de sementes de videira cv. niágara rosada. As médias seguidas da mesma letra e que correspondem à mesma combinação dos tratamentos não diferem entre si, pelo teste de Tukey, a 5\% de probabilidade.

corte das sementes na região da micrópila foi superior ao corte na metade, em ambiente in vitro, com tratamento de $\mathrm{GA}_{3}$ (Figura 4). Entretanto, esse efeito se limita a essa combinação de fatores. Contudo, o melhor desempenho do processo de germinação observado com o corte na região da micrópila das sementes pode ser devido à localização do embrião da videira, o qual se encontra próximo à região da micrópila. O corte nessa região expõe, diretamente, o embrião ao meio de cultura, além de contribuir para a sua expulsão do interior da semente. Segundo Ellis et al. (1983), métodos atualmente empregados para germinação de sementes de videiras raramente proporcionam porcentagens superiores a 50\%. Pommer et al. (1988) obtiveram no máximo 53,2\% de germinação de sementes de videira niágara rosada, combinando estratificação por 60 dias e $2.000 \mathrm{mg} \mathrm{L}^{-1} \mathrm{de} \mathrm{GA}_{3}$. Segundo os mesmos autores, existe tendência natural

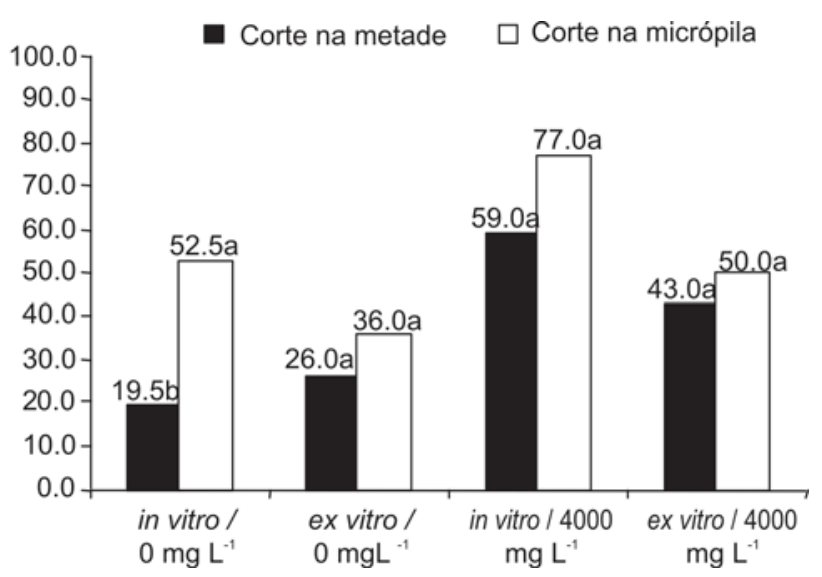

Figura 4. Efeito dos tratamentos físicos na porcentagem de germinação de sementes de videira cv. niágara rosada. As médias seguidas da mesma letra e que correspondem à mesma combinação dos tratamentos não diferem entre si, pelo teste de Tukey, a 5\% de probabilidade.

das sementes de $V$. labruscana, incluindo niágara rosada, de apresentar baixa porcentagem de germinação. No presente trabalho, a porcentagem máxima de germinação foi de $77 \%$, considerada alta se comparada aos resultados obtidos por outros autores (Scott \& Ink, 1950; Ottenwaelter et al.,1974; Pommer et al., 1988; Ergenoglu et al., 1997). Esta porcentagem de germinação foi alcançada, basicamente, pela combinação dos tratamentos com $4000 \mathrm{mg} \mathrm{L}^{-1}$ de $\mathrm{GA}_{3}$, corte da semente na região da micrópila e ambiente de germinação in vitro

Nesse caso, o ambiente in vitro foi estatisticamente superior quanto à germinação das sementes, em comparação ao ambiente ex vitro (Figura 5). Nesse ambiente, a germinação dessas sementes foi superior em 27 pontos percentuais com relação ao ambiente ex vitro (Figura 5). Provavelmente em função da melhor disponibilidade de água e nutrientes e do melhor controle de contaminações e do potencial osmótico, proporcionados em ambientes in vitro (Vasquez-Yanes \& OrozcoSegovia, 1996).

$\mathrm{O}$ efeito do $\mathrm{GA}_{3}$ foi significativo na porcentagem de germinação das sementes de uva (Figura 6). Em ambiente in vitro, a aplicação de $4000 \mathrm{mg} \mathrm{L}^{-1}$ de $\mathrm{GA}_{3}$ aumentou em 39,5 e 24,5\%, respectivamente, a germinação de sementes cortadas ao meio e na região da micrópila (Figura 6). Já a variação da porcentagem de germinação de sementes devido ao $\mathrm{GA}_{3}$, em ambiente ex vitro, não foi significativa.

$\mathrm{O}$ efeito positivo do $\mathrm{GA}_{3}$ pode ser devido ao papel fundamental das giberelinas na quebra de dormência e promoção da germinação de sementes de videira (Celik, 2001). A função do $\mathrm{GA}_{3}$ na quebra de dormência das sementes está associada à promoção de estímulos que induzem a síntese ou a ativação das enzimas hidrolíticas no endosperma (Mayer \& Mayber, 1975; Amen, 1987; Taiz \& Zeiger, 1998). Com a aplicação de $\mathrm{GA}_{3}$ às sementes, prova- 


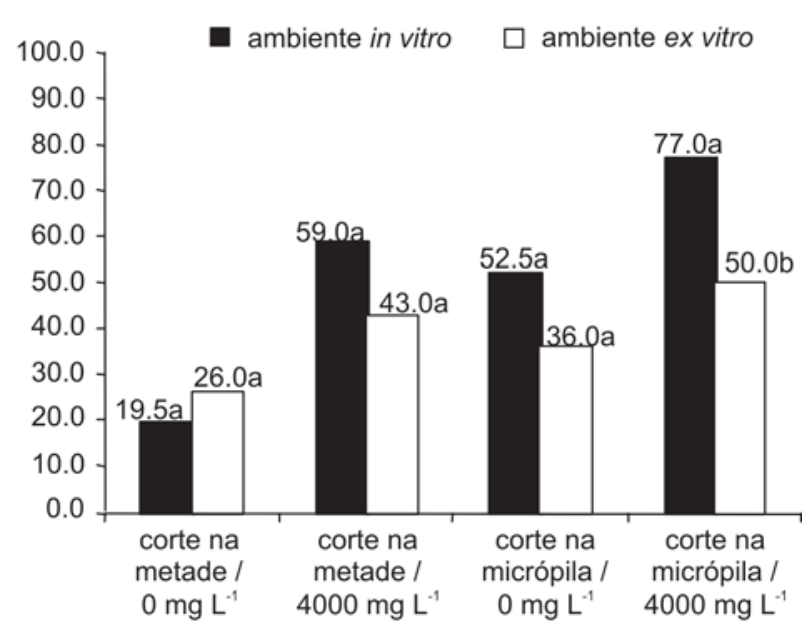

Figura 5. Efeito do ambiente na porcentagem de germinação de sementes de videira cv. niágara rosada. As médias seguidas da mesma letra e que correspondem à mesma combinação dos tratamentos não diferem entre si, pelo teste de Tukey a $5 \%$ de probabilidade

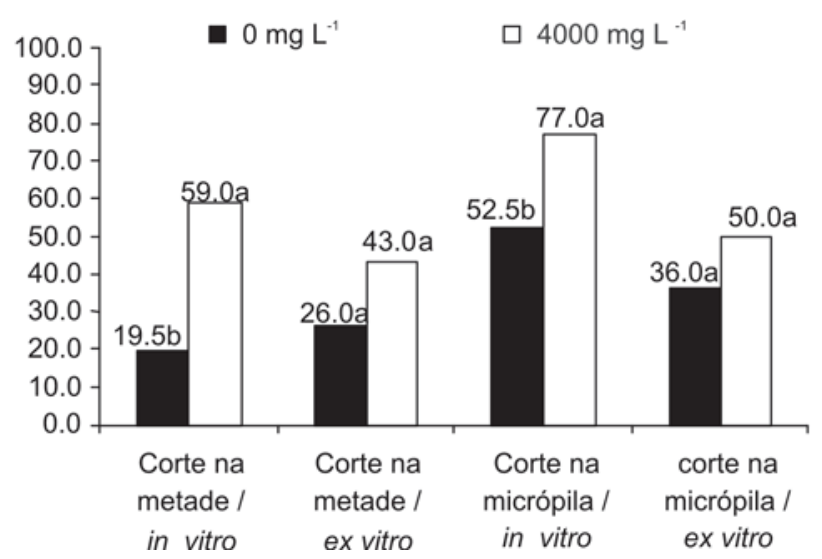

Figura 6. Efeito das concentrações de ácido giberélico na porcentagem de germinação de sementes de videira cv. niágara rosada. As médias seguidas da mesma letra e que correspondem à mesma combinação dos tratamentos não diferem entre si, pelo teste de Tukey, a nível de $5 \%$ de probabilidade

velmente ocorreu indução da germinação. Entretanto, sementes com embriões sem vigor ou desprovidas de reservas podem ter sucumbido durante o processo de germinação. Contudo, em ambiente in vitro essas sementes encontraram nutrientes e condições necessárias ao seu desenvolvimento, o que não ocorreu em ambiente ex vitro. Portanto, a porcentagem de germinação de sementes tratadas com ácido giberélico foi estatisticamente superior em ambiente in vitro, provavelmente por esse ambiente permitir o desenvolvimento de plântulas oriundas de sementes desprovidas de reservas.

\section{CONCLUSÕES}

A aplicação dos cortes, tanto na metade como na micrópila de sementes de videira cv. niágara rosada, foi essencial à germinação. Eles podem substituir o processo de estratificação das sementes para a germinação in vitro de sementes de uva.
Ambos os cortes nas sementes reduziram drasticamente o tempo de germinação, em comparação ao dos métodos utilizados atualmente.

A combinação ambiente in vitro, aplicação de ácido giberélico e corte na região da micrópila propiciou o maior índice de germinação de sementes (77\%).

\section{REFERÊNCIAS}

Amen RD (1987) The effects of gibberellic acid and scarification on the seed dormancy and germination of Luzula spicata. Physiologia Platarum, 20:6-12.

Carvalho NM de \& Nakagawa J (2000) Sementes: ciência, tecnologia e produção. 4. ed. Jaboticabal, Funep. 588p.

Celik H (2001). Effect of bottom heating, germination medium and gibberelic acid treatments ongermination of Isabella (Vitis labrusca L.) grapes seeds. Pakistan Journal of Biological Sciences. 4:953-957.

Ellis RH, Hong TD \& Roberts EH (1983) A note on the development of a practical procedure for promoting the germination of dormant seed of grape (Vitis spp.) Vitis, 22:211219.

Ergenoglu F, Tangolar S \& Gök S (1997) The effects of some pretreatments for promoting germination of grape seeds. Acta Horticulturae, 44:207-212.

Gray JD \& Meredith CP (1992) Grape. In: Hammerschlag FA \& Litz RE (Eds.) Biotechnology of perennial fruits crops. Wallingford, CAB International. p.229-262.

Mayer AM \& Mayber AP (1975) The germination of seeds. 2. ed., Oxford, Pergamon. 192p.

Murashige T \& Skoog F (1962) A revised medium for rapid growth and bioassays with tobacco tissue cultures. Physiologia Plantarum, 15:473-479.

Ottenwaelter MM, Boussion C, Doazan JP \& Rives MA (1974) Technique for improving the germinability of grapes seeds for breeding purposes. Vitis, 13:1-3.

Pommer CV, Maeda IA \& Ribeiro IJA ( 1988) Capacidade de germinação e quebra de dormência em sementes de cultivares de videira. Bragantia, 47:143-157.

Reisch IB \& Pratt C (1996) Grapes. In: Janickes J \& Moore JN (Eds.) Fruit breeding. New York, vol. II, p.297-369.

Scott DH \& Ink DP (1950) Grape seed germination experiments. Proceedings of the American Society for Horticultural Science, 56:134-139.

Taiz L \& Zeiger E (1998) Plant Physiology. 2 ed. Sunderlands, Sinauer Associates. 792p.

Terra MM, Pires EJP \& Nogueira NAM (1993) Tecnologia para produção de uva 'itália' na região noroeste do Estado de São Paulo. Campinas, Coordenadoria de Assistência Técnica Integrada (CATI). 51p.

Vazquez-Yanes C \& Orozco-Segovic A (1996) Comparative longetivy of seeds of five tropical rain forest wood species stored under different moisture conditions.Canadian Journal of Botany, 74:1635-1639.

Vieira RD \& Carvalho NM de (1994) Testes de vigor em sementes. Jaboticabal, FUNEP. 164p.

White PR (1951) Nutricional requirements of isolated plant tissue and organs. Annual Review of Plants Physiology, 2:213-244. 